\title{
Reuna
}

\section{EFEITOS DA CRISE ECONÔMICA SOBRE O COMPORTAMENTO DO CONSUMIDOR}

\section{EFFECTS OF ECONOMIC CRISIS ON CONSUMER BEHAVIOR}

\author{
http://dx.doi.org/10.21714/2179-8834/2019v24n3p41-63
}

\begin{abstract}
Alexandra Bastos Cerqueira Vieira
Universidade Fumec, Brasil.

E-mail: alexandra.bastos@gvieira.com.br

José Marcos Carvalho de Mesquita

University of Connecticut, United States

E-mail: josemcmesquita@gmail.com

Wilson José Vieira da Costa

Instituto Federal de Minas Gerais (IFMG) e Faculdade de Engenharia de Minas Gerais (FEAMIG), Brasil.

E-mail: wilsoncosta@feamig.br e wilson.costa@ifmg.edu.br
\end{abstract}

Submissão: 14 Jan. 2019 Publicação: 02 Nov. 2019. Sistema de avaliação: Double blind review.

Centro Universitário UNA, Belo Horizonte - MG, Brasil. Editor geral: Prof. Dr. Gustavo Quiroga Souki

Este artigo encontra-se disponível nos seguintes endereços eletrônicos:

http://revistas.una.br/index.php/reuna/article/view/1026

http://dx.doi.org/10.21714/2179-8834/2019v24n3p41-63

\section{Resumo}

O presente estudo teve como objetivo pesquisar o comportamento de consumo das pessoas de diferentes classes econômicas diante de um cenário de recessão econômica, cenário atual da economia brasileira. Foram estudadas as relações existentes entre os construtos motivação, percepção, crenças e atitudes, aprendizagem, estilo de vida e comportamento de compra. Foi realizada uma pesquisa de campo com 198 respondentes na cidade de Belo Horizonte, acessados pessoalmente ou via questionário eletrônico. Constatou-se que, quanto maior a motivação, percepção, crenças e atitudes, maior será a influência sobre o comportamento de compra. Não houve influência significativa da aprendizagem e do estilo de vida sobre o comportamento de compra. Pode-se concluir que os fatores pessoais demográficos, representados pelos grupos 1 (indivíduos mais velhos, casados ou em união estável, com pós-graduação, e classes sociais mais altas) e grupo 2 (indivíduos mais jovens, solteiros, com escolaridade superior ou menor e de classes sociais mais baixas) não exerceram influência na relação da motivação, da percepção, da aprendizagem, das crenças e atitudes e do estilo de vida com o comportamento de compra.

Palavras-chave: Economia. Recessão. Comportamento do Consumidor. Motivação. Crenças e Atitudes. 


\begin{abstract}
The present study aimed to investigate the consumption behavior of people from different economic classes in the face of a scenario of recession such as the one we are currently experiencing. We studied the relationships between the constructs motivation, perception, beliefs and attitudes, learning, lifestyle versus purchase behavior. A field survey was conducted with 198 respondents in the city of Belo Horizonte, accessed personally or through an electronic questionnaire. It has been found that the greater the motivation, perception, beliefs and attitudes, the greater will be the influence on buying behavior. There was no significant influence of learning and lifestyle on buying behavior. It can be concluded that the demographic personal factors, represented by groups 1 (older individuals, married or in stable union, with graduate, master's or doctorate and group 2 (young, single, undergraduate or a lesser educational level and lower social classes) did not influence the relation of motivation, perception, learning, beliefs and attitudes and lifestyle with buying behavior.
\end{abstract}

Keywords: Economy. Recession. Consumer Behavior. Motivation. Beliefs and Attitudes.

\title{
1. Introdução
}

O comportamento do consumidor é influenciado por fatores internos e externos, sendo um dos fatores externos as condições econômicas do país. Em períodos de crise econômica, os padrões de comportamento no ato da compra tendem a se modificar em relação a períodos de prosperidade econômica. Flatters e Willmott (2009) identificaram tendências no consumo em momentos de crise econômica. São elas: consumo simplificado, baseado em hábitos modestos; poupança ilimitada, mesmo famílias de alta renda poupam; consumo "mercurial" - os consumidores, reagem muito rapidamente às mudanças de preço, com busca por produtos mais baratos; redução do consumo "verde"; redução do consumo ético - pessoas doam menos para a caridade e causas similares.

Segundo Koksal e Ozgul (2007), as estratégias comumente utilizadas por empresas em períodos de crise passam por reduções de custos, cortes na produção, redução do investimento e entrada em novos mercados. Essas medidas tendem a impactar negativamente a economia do país, provocando redução na renda e, consequentemente, no consumo. Mansoor e Jalal (2011) e Teixeira (2015) confirmam tal fato, mostrando que em tempos de crise, os consumidores tendem a modificar o seu comportamento de compra em consequência das implicações financeiras que chegam concomitantemente com a instabilidade econômica. Portanto, a maioria dos consumidores tem de reconsiderar os seus hábitos de consumo e realocar o seu orçamento. Meyer e Sullivan (2013) observaram que durante a recessão econômica americana que se seguiu à crise de 2008, a desigualdade no consumo cresceu menos do que a desigualdade na renda, mostrando que em períodos de crise, reduções de consumo tendem a se espalhar e atingir grande parte da população.

Pode-se perceber que as pessoas não conseguem manter o mesmo comportamento de compra em momentos de crise econômica e em momentos de estabilidade ou crescimento da economia (De Nardi, French, e Benson, 2011). Fatores 
psicológicos e pessoais irão influenciar esse processo de escolha. Logo, conhecer o que querem os consumidores e como eles tomam suas decisões sobre a compra e a utilização de produtos é fundamental para que as organizações tenham êxito em seu mercado (SHETH, MITTAL, \& NEWMAN, 2001). Apesar de muitas pesquisas avaliarem os fatores determinantes do comportamento do consumidor, estudos que contemplem mudanças comportamentais devido aos efeitos de crises econômicas ainda são raros (KAYTAZ e GUL, 2014).

Diante do contexto apresentado, deriva-se a questão que norteia a pesquisa: quais alterações ocorrem no comportamento de compra em períodos de recessão econômica? Portanto, com o presente estudo objetivou-se analisar quais alterações ocorrem no comportamento de compra do consumidor final, em um período de crise econômica, e quais são os aspectos causadores dessas modificações.

\section{Referencial Teórico}

Os modelos clássicos de comportamento do consumidor dividem o processo de compra do consumidor em cinco etapas: reconhecimento da necessidade, busca de informações, avaliação de alternativas, decisão de compra e avaliação pós-compra (SCHIFFMAN e KANUK, 2012; SHETH; MITTAL; NEWMAN, 2001). Tais autores mostram que o processo de compra do consumidor é influenciado por diversos fatores, internos ou externos ao comprador, dentre os quais destacam-se para os propósitos da presente pesquisa: culturais, sociais, pessoais e psicológicos.

\section{1 $\quad$ Fatores psicológicos}

Segundo Sheth, Mittal e Newman (2001), os fatores psicológicos dizem respeito ao conjunto das funções cognitivas (pensamentos), conativas (comportamento) e afetivas (sentimentos) durante o processo de compra. Assim, para poder entender esses fatores psicológicos, é preciso aprofundar o estudo em diversas áreas, como: motivação, percepção, aprendizagem e crenças e atitudes.

\subsubsection{Motivação}

Schiffman e Kanuk (2012, p. 62) afirmam que a motivação é considerada uma força psicológica, definida como "força impulsionadora que existe dentro dos indivíduos e que os impele à ação". A força impulsionadora é determinada por uma situação de tensão e nada mais é do que uma necessidade insatisfeita.

Dreger, Araújo e Espartel (2017) identificam algumas formas de motivação. Uma delas é a motivação utilitária, que se refere a uma motivação primária de compra direcionada à procura de um ou mais produtos ou serviços específicos. A outra forma é a motivação hedônica, quando o cliente tem por motivação o hedonismo, em que o seu foco está mais na experiência de consumo e nos sentimentos prazerosos que este pode lhe proporcionar do que no tipo de produto ou em algum objetivo específico. 
Para Sheth, Mittal e Newman (2001), as expectativas otimistas e pessimistas do cliente em relação ao futuro irão estimular ou inibir os seus gastos. Parte-se da premissa de que, em períodos de crise econômica, as pessoas se sentem desmotivadas a consumir, ao passo que, em períodos de estabilidade ou desenvolvimento econômico, as pessoas estão propensas a consumir mais, devido a fatores como o aumento do crédito, a queda da inflação e dos juros, entre outras variáveis a serem consideradas. Logo, espera-se que, em períodos de recessão econômica:

H1: Existe um efeito positivo da motivação sobre as alterações do comportamento de compra.

\subsubsection{Percepção}

O estudo do comportamento do consumidor explora com grande ênfase os fatores internos que nele provocam as ações de compra de um produto ou serviço. Porém a percepção que o consumidor tem de um produto ou serviço fará toda a diferença na hora de optar por comprá-lo ou não.

Para Guillen et al. (2012), percepção é o processo por meio do qual os indivíduos interpretam as informações que afetam seus sentimentos e ações, bem como os de outras pessoas, portanto não é necessariamente igual à realidade, pois lhes fornece apenas um significado limitado, próprio de cada ser humano. A percepção é construída pela familiaridade - conjunto de experiências vivenciadas pelos indivíduos, sua cultura e habilidade cognitiva. Dessa forma, as percepções e respostas de duas pessoas não serão necessariamente as mesmas quando descreverem um mesmo fato.

Para Silva (2015), todo o cenário provocado pela crise financeira e econômica veio gerar na população grande instabilidade e insegurança, levando-a a ter um comportamento de retração em relação ao consumo de bens e serviços. A crise levou as famílias a gastarem menos e a pouparem mais. Com base nessa lógica, sugere-se que:

H2: Existe um efeito positivo da percepção sobre as alterações do comportamento de compra.

\subsubsection{Aprendizagem}

Schiffman e Kanuk (2012, p.137) entendem a aprendizagem do consumidor como "[...]o processo pelo qual os indivíduos adquirem o conhecimento e a experiência de compra e consumo que aplicam a um comportamento correlato futuro".

Em momentos de crise econômica, a aprendizagem oriunda de experiências negativas, tais como privação, descontrole orçamentário e endividamento, pode levar a uma queda no consumo. Silva (2015) ressalta que, em momentos de crise econômica, o consumidor passa a ter uma postura distinta e mais retraída no ato de consumir, assumindo, assim, o papel de novo consumidor na sociedade. Entretanto, esse comportamento não foi confirmado por Alonso, Rodríguez e Rojo (2015). Os autores mostram que consumidores de maior poder aquisitivo e mais jovens não se 
sentiram motivados a reduzir o padrão de consumo durante a crise que assolou a economia espanhola a partir de 2008. Entende-se que esse comportamento é típico de um grupo especifico e, portanto, pressupõe-se que:

H3: Existe um efeito positivo da aprendizagem sobre as alterações do comportamento de compra.

\subsubsection{Crenças e atitudes}

A atitude de escolha de um consumidor está ligada às suas crenças e aos valores que ele dá a um objeto ou serviço. Existe um sistema de valores nas culturas que é composto por valores relativos, ou seja, os consumidores possuem valores que direcionam seu comportamento de consumo a partir da crença de que alguma condição é preferível a outra oposta (SCHIFFMAN e KANUK, 2012; SHETH; MITTAL; NEWMAN, 1999).

As atitudes definem se uma pessoa gosta ou não de uma coisa, e se aproxima ou se distancia dela. Em momentos de crise econômica, os consumidores ficam mais avessos ao risco e tendem a consumir menos (FILIPE, BARBOSA, e AMADO, 2015; KAYTAZ e GUL, 2014). Essa atitude reflete a sua crença adquirida de experiências passadas ou de informações atuais de que é necessário ter cautela no consumo em momentos de instabilidade na economia. A partir daí, sugere-se que:

H4: Existe um efeito positivo das crenças e atitudes sobre as alterações do comportamento de compra.

\subsection{Fatores pessoais}

Os fatores pessoais podem ser divididos em dois grupos: os fatores pessoais psicológicos relacionados à personalidade e ao estilo de vida das pessoas e os fatores pessoais demográficos que compreendem a idade e o estágio do ciclo de vida, a ocupação, as condições econômicas.

\subsubsection{Fatores pessoais psicológicos}

\subsubsection{Personalidade}

A personalidade se refere às características, respostas emocionais, pensamentos e comportamentos que são relativamente estáveis ao longo do tempo em diferentes circunstâncias (SCHIFFMAN e KANUK, 2012; SHETH; MITTAL; NEWMAN, 2001).

Basso, Reck e Rech (2013) afirmam que a personalidade contém em seu escopo a ideia de que cada indivíduo tem a sua organização de personalidade. Ao analisar diversos indivíduos, no entanto, nota-se que determinados padrões emergem de características semelhantes. Esses autores afirmam que o uso da personalidade em pesquisas de marketing pode ser mais aprofundado, provendo explicações mais 
sólidas que permitam um maior direcionamento das empresas e de seus consumidores, especialmente ao se tentar identificar a relação com o estilo de vida.

\subsubsection{Estilo de vida}

O estilo de vida é o comportamento de uma pessoa referente a suas atividades, seus interesses e suas opiniões. Ele envolve não somente a sua classe social ou a sua personalidade, mas define o padrão de ação e de interação da pessoa com a sociedade.

Para Secco, Oliveira e Amorim (2014), o estilo de vida demonstra o comportamento pessoal do indivíduo, já que este interage com seu meio. Com isso, as empresas sempre desejam que seus produtos, de alguma forma, estejam ligados ao estilo de vida do seu público-alvo.

O próprio indivíduo tem consciência de que se comunica por meio de suas roupas, de sua casa - significado do mobiliário, dos objetos de decoração -, de seu carro, de suas atividades de lazer, dos lugares que frequenta, e que esses elementos, ou o conjunto desses elementos, serão interpretados e classificados em termos da presença ou da falta de gosto (CORREA e PINTO, 2014).

McCracken (2007) afirma que o indivíduo compra com a finalidade de pertencer e de fazer parte de um estilo de vida ideal. A compra tem a qualidade de evocação desse pertencimento, a compra é o "consumo em exercício". Com base nessa lógica, sugere-se que:

H5: Existe um efeito positivo do estilo de vida sobre as alterações do comportamento de compra.

\subsubsection{Fatores pessoais demográficos}

\subsubsection{Idade e estágio do ciclo de vida}

Conforme as pessoas vão passando pelos estágios de vida, vão criando novos hábitos e abrindo mão de outros, surgem novos gostos e interesses. Para Mendes e Aquino (2015), esses dois aspectos - idade e estágio no ciclo de vida - são relevantes para o entendimento do comportamento de compra das pessoas e para as mudanças e variações que esse comportamento sofre ao longo da vida dos indivíduos. Percebese que cada etapa da vida de uma pessoa gera um tipo de interesse por determinado produto. "Um indivíduo muda sua cesta de consumo conforme sua idade, pois suas necessidades migram, não são sempre as mesmas" (SCHIFFMAN e KANUK, 2012; SHETH; MITTAL; NEWMAN, 2001).

Ao mesmo tempo, o comportamento do consumidor também se torna diferenciado em situações específicas, como em uma crise econômica (FLATTERS e WILLMOTT, 2009). Partindo desses pressupostos, verifica-se que, quanto mais velha for a pessoa, maior será sua aversão ao risco e, consequentemente, ela reduzirá o seu consumo, principalmente em momentos de crise econômica. Portanto pressupõe-se 
que pessoas de idade próximas tendem a ter semelhanças em seus comportamentos de consumo em momentos de crise financeira.

\subsubsection{Ocupação}

O papel que uma pessoa desempenha em determinado grupo social, bem como seu status, tem grande influência no comportamento de compra do consumidor. "Variáveis como profissão, ocupação e condições econômicas definem status e o poder aquisitivo, trazendo consigo uso e consumo de produtos específicos" (GADE, 2010, p. 172). O tema status é bastante debatido nos dias atuais e de relevante importância para os estudiosos de marketing, pois trabalha com a imagem que a pessoa quer passar perante determinado grupo de identificação.

Verifica-se que a profissão que o consumidor exerce influencia o seu padrão de consumo. Assim, advogados usarão terno em seus postos de trabalho, médicos suas tradicionais roupas brancas, enquanto educadores físicos utilizam roupas esportivas.

A identidade é segmentada, o indivíduo participa, concomitantemente, de vários grupos de referência social, independentemente do espaço e do lugar. Assim, o ser humano se relaciona de acordo com os outros e com seus interesses pessoais (BARBOSA, 2008).

A partir daí, acredita-se que pessoas que apresentam a mesma ocupação, por pertencerem ao mesmo grupo social, tendem a ter comportamentos semelhantes no consumo em momentos de recessão econômica.

\subsubsection{Classe Econômica}

A situação financeira de uma pessoa afeta sua escolha do produto. KorickaGebska e Gebski (2013) consideram que a crise econômica tem impacto automático no comportamento do consumidor. Isso porque a maior consequência da crise econômica é a diminuição do rendimento disponível por parte do agregado familiar, o que implica a necessidade de adaptação desse mesmo rendimento aos produtos e serviços que pode comprar ou usufruir, levando a uma mudança nas preferências do consumidor. Logo, em períodos de recessão econômica, a renda tende a cair, consequentemente, o consumo pessoal é o primeiro a sentir esse impacto e se reduz. Com base no referencial exposto acima, sugere-se que:

H6: Existe um efeito moderador dos fatores pessoais sobre as alterações do comportamento de compra.

\section{Procedimentos metodológicos}

Quanto aos fins, esta pesquisa se classifica como descritiva. Na pesquisa descritiva, realiza-se o estudo, a análise, o registro e a interpretação dos fatos do mundo físico, sem a interferência do pesquisador. Quantos aos meios, foi realizada um survey, com aplicação de questionários. 
A pesquisa foi realizada com 198 indivíduos na cidade de Belo Horizonte, que responderam ao questionário contendo 43 variáveis, sendo 10 variáveis de caracterização da amostra e 33 variáveis relacionadas aos seis construtos (Motivação, Percepção, Aprendizagem, Crenças e Atitudes, Estilo de Vida, Comportamento de Compra).

A coleta dos dados foi realizada no período de 11 de novembro de 2016 a 28 de novembro de 2016, sendo que todos os respondentes tiveram como condição essencial serem moradores do município de Belo Horizonte.

A técnica de amostragem utilizada foi por conveniência, sendo que foram abordados consumidores disponíveis em espaços públicos. Também foram utilizados questionários online.

Anteriormente à coleta de dados, foi realizado um pré-teste, com a coleta de dez casos por meio de entrevista pessoal para avaliação prévia da validade e confiabilidade dos construtos, de modo a se fazerem as adequações ao objetivo da pesquisa. Convém ressaltar que os questionários utilizados na realização do pré-teste foram descartados devido às modificações que foram feitas no instrumento original.

A escala utilizada variou de (1) discordo totalmente a (5) concordo totalmente. No construto personalidade, a partir de autores como Basso, Reck e Rech (2013), Avelar e Veiga (2013), foram consideradas as variáveis abertura às novas experiências, materialismo, necessidade de recursos físicos, necessidade de aprendizado, competitividade, necessidade de diversão etc. O estilo de vida foi avaliado a partir da percepção populacional referente à influência dos seguintes fatores comportamentais: atitudes (refere-se a ações como hobbies, eventos sociais, férias, entretenimento, comunidades), interesses do entrevistado (importância da família, do trabalho, da comunidade, lazer têm na vida do entrevistado), opiniões (política, economia, futuro, etc.) e seus valores (forma que orientam a maneira como os entrevistados conduzem à sua vida relacionadas ao consumo pessoal). Autores como Secco, Oliveira e Amorin (2011) sustentam o questionário.

Já nos fatores psicológicos foram abordadas as variáveis motivações, percepção, aprendizagem e crenças e atitudes. Com base em Marino e Sampaio (2013) e Dreger (2017), inicia-se o questionário sobre o aspecto motivacional avaliando o processo de compra para satisfazer uma necessidade ou um desejo do indivíduo. De acordo com Dreger (2017), a motivação pode estar direcionada a produtos específicos (necessidade) ou estar direcionada pela busca do prazer (desejo). Apoiado em Dreger (2017), pretendeu-se analisar o desejo de se atingir a felicidade, aumentar a autoestima e a realização na hora das compras.

Marino e Sampaio (2013) relatam a importância do segundo passo na hora da compra depois do reconhecimento da necessidade. É a busca por informações. Nesse momento fatores como preço, qualidade, promoções, instabilidade financeira podem ser um diferencial na decisão de compra. O questionário analisou se em um ambiente de confiança e livre de más notícias as pessoas se sentem mais motivadas a gastarem.

No construto percepção, a partir de Guillen (2012) e De Toni (2007), foram abordados quais foram os efeitos imediatos sentidos pelo consumidor com a crise econômica (desemprego, inflação, queda da renda) e sua percepção relativa ao que esperar do futuro da economia brasileira. 
$\mathrm{Na}$ aprendizagem foi analisada a importância que o entrevistado dá às notícias sobre economia e aos fatores que influenciam a sua mudança de comportamento no que diz respeito ao consumo. No aspecto de crenças e atitudes, o comportamento do consumidor relativo a suas atitudes em momentos de crise, o impacto das suas crenças na sua decisão de compra e a sua reação emocional durante um período de estagnação. Sheth, Mittal e Newman (2001) e Schiffman e Kanuk (2012) serviram de sustentação para o estudo.

O construto comportamento de compra avaliou as mudanças ocorridas devido à recessão econômica, ou seja, buscou-se mensurar quais foram as alterações no comportamento de compra provocadas pela crise econômica. O questionário pode ser visto na Tabela 1.

A fim de avaliar a relação entre os construtos, foi utilizado o modelo de equações estruturais utilizando a abordagem Partial Least Square (PLS).

Para avaliar o efeito moderador das variáveis pessoais nas relações sobre o construto comportamento de compra, optou-se por criar uma variável que sintetizasse os fatores pessoais-demográficos. Essa variável foi criada a partir do agrupamento dos indivíduos com comportamentos similares em relação às variáveis pessoaisdemográficas (Idade, Estado Civil, Escolaridade e Classe Social). O agrupamento foi realizado por meio de Análise Hierárquica de Agrupamento (HAIR JR. et al., 2009), via Método de Ward, com coeficiente de similaridade de Gower (GOWER, 1971), que é adequado para o cálculo da similaridade quando há dados qualitativos.

$\mathrm{Na}$ análise hierárquica de agrupamento optou-se por trabalhar com dois grupos. O Grupo 1 caracterizou-se por apresentar, principalmente, indivíduos mais velhos, casados ou em união estável, com pós-graduação, mestrado ou doutorado e pertencentes a classes econômicas mais altas. O Grupo 2 caracterizou-se por apresentar, principalmente, indivíduos mais jovens, solteiros, com escolaridade igual a "nível médio ou $2^{\circ}$ grau técnico" e "graduação" e pertencentes a classes econômicas mais baixas. O software utilizado nas análises foi o $R$ (versão 3.3.1).

\section{Resultados e discussão}

Com relação ao perfil da amostra, 55,38\% dos indivíduos eram do sexo feminino, enquanto $44,62 \%$ eram do sexo masculino. Constata-se que a maior parte dos indivíduos tinha de 19 a 29 anos $(32,14 \%)$ e de 30 a 39 anos $(29,59 \%)$; as faixas de renda familiar mensal mais frequentes foram de 5 a 15 salários mínimos $(42,41 \%)$ e mais de 15 salários mínimos (19,37\%). 48,72\% dos indivíduos eram casados/união estável e solteiros (43,08\%). As escolaridades mais frequentes foram Pós-Graduação, Mestrado ou Doutorado (40,00\%) e Graduação (30,77\%).

A análise descritiva dos itens dos construtos é mostrada na Tabela 1. Cabe ressaltar que os itens foram recodificados de forma que variassem de -1 (discordo totalmente) a 1 (concordo totalmente). Os intervalos de confiança estritamente negativos evidenciam discordância com o item, enquanto intervalos estritamente positivos indicam concordância e intervalos que contêm o zero não evidenciam nem concordância nem discordância. 


\section{Reuna}

Tabela 1 - Análise descritiva dos itens dos construtos

\begin{tabular}{|c|c|c|c|c|}
\hline & Construtos & Média & D.P. & I.C. $-95 \%$ \\
\hline \multicolumn{5}{|c|}{ Motivação } \\
\hline MOT1 & Mesmo com a crise, gosto de comprar para satisfazer uma necessidade (produtos básicos). & 0,32 & 0,69 & {$[0,22 ; 0,41]$} \\
\hline MOT2 & Mesmo com a crise, gosto de comprar para satisfazer um desejo (produtos sofisticados). & $-0,31$ & 0,70 & {$[-0,42 ;-0,22]$} \\
\hline МOT3 & Para você comprar, é necessário um ambiente de confiança. & 0,52 & 0,63 & {$[0,42 ; 0,60]$} \\
\hline MOT4 & Para você comprar, é necessário um ambiente livre de más notícias. & 0,29 & 0,69 & {$[0,20 ; 0,39]$} \\
\hline MOT5 & Comprar me deixa feliz. & 0,29 & 0,67 & {$[0,20 ; 0,39]$} \\
\hline MOT6 & Comprar aumenta minha auto-estima. & 0,10 & 0,74 & {$[-0,01 ; 0,19]$} \\
\hline MOT7 & Comprar me deixa realizado. & 0,12 & 0,71 & {$[0,02 ; 0,22]$} \\
\hline \multicolumn{5}{|c|}{ Percepção } \\
\hline PER1 & O desemprego aumentou. & 0,84 & 0,45 & {$[0,77 ; 0,90]$} \\
\hline PER2 & Os preços aumentaram. & 0,76 & 0,49 & {$[0,69 ; 0,83]$} \\
\hline PER3 & A renda das pessoas diminuíram. & 0,58 & 0,57 & {$[0,50 ; 0,66]$} \\
\hline PER4 & As pessoas estão comprando menos. & 0,47 & 0,61 & {$[0,38 ; 0,56]$} \\
\hline PER5 & Estamos vivenciando uma crise econômica, mas já está passando. & $-0,31$ & 0,61 & {$[-0,39 ;-0,22]$} \\
\hline PER6 & Estamos vivenciando uma crise econômica, que deve durar por um bom tempo. & 0,33 & 0,62 & {$[0,25 ; 0,42]$} \\
\hline \multicolumn{5}{|c|}{$\begin{array}{l}\text { Aprendizagem } \\
\end{array}$} \\
\hline APR1 & Acho importante assistir/ler/escutar noticiários sobre economia. & 0,75 & 0,48 & {$[0,68 ; 0,81]$} \\
\hline APR2 & Gosto de conversar com amigos sobre economia. & 0,27 & 0,67 & {$[0,17 ; 0,35]$} \\
\hline APR3 & Mudei meu comportamento de consumo devido a experiências passadas. & 0,36 & 0,66 & {$[0,26 ; 0,44]$} \\
\hline APR4 & Mudei meu comportamento de consumo devido a experiências de amigos. & $-0,11$ & 0,68 & {$[-0,20 ;-0,02]$} \\
\hline \multicolumn{5}{|c|}{$\begin{array}{ll}\text { Crenças e atitudes } \\
\end{array}$} \\
\hline CEA1 & Creio que a crise vai durar muito tempo. & 0,28 & 0,63 & {$[0,20 ; 0,37]$} \\
\hline CEA2 & Creio que a crise ainda vai se agravar. & $-0,23$ & 0,64 & {$[-0,32 ;-0,15]$} \\
\hline CEA3 & Creio que a crise vai me afetar. & 0,32 & 0,60 & {$[0,23 ; 0,39]$} \\
\hline CEA4 & Devo me preocupar com o futuro. & 0,76 & 0,50 & {$[0,68 ; 0,83]$} \\
\hline
\end{tabular}


Tabela 1 - Análise descritiva dos itens dos construtos (continuação)

\begin{tabular}{|c|c|c|c|c|}
\hline \multicolumn{5}{|c|}{ Estilo de vida } \\
\hline EDV1 & Dou muito valor ao relacionamento com os familiares. & 0,79 & 0,44 & {$[0,73 ; 0,85]$} \\
\hline EDV2 & Dou muito valor ao relacionamento com os amigos. & 0,68 & 0,48 & {$[0,61 ; 0,75]$} \\
\hline EDV3 & Gosto muito de me divertir comprando. & $-0,10$ & 0,69 & {$[-0,19 ;-0,01]$} \\
\hline EDV4 & Gosto muito de conforto material. & 0,21 & 0,60 & {$[0,12 ; 0,29]$} \\
\hline EDV5 & Gosto de impressionar as pessoas com os produtos que compro. & $-0,55$ & 0,60 & {$[-0,63 ;-0,46]$} \\
\hline EDV6 & Me preocupo em guardar dinheiro para situações imprevistas. & 0,51 & 0,61 & {$[0,43 ; 0,59]$} \\
\hline \multicolumn{5}{|c|}{ Comportamento de compra } \\
\hline CDC1 & Altero a periodicidade das compras. & 0,31 & 0,62 & {$[0,23 ; 0,40]$} \\
\hline CDC2 & Passo a ter mais em conta o preço quando compro. & 0,41 & 0,60 & {$[0,32 ; 0,49]$} \\
\hline CDC3 & Considero que a crise influenciou o meu consumo. & 0,45 & 0,63 & {$[0,36 ; 0,54]$} \\
\hline CDC4 & Diminuo o consumo de alguns produtos. & 0,45 & 0,60 & {$[0,36 ; 0,53]$} \\
\hline CDC5 & Substituo o consumo de um produto por outro mais barato. & 0,48 & 0,62 & {$[0,39 ; 0,56]$} \\
\hline CDC6 & Reorganizo o orçamento. & 0,59 & 0,53 & {$[0,52 ; 0,66]$} \\
\hline
\end{tabular}

Fonte: Dados da pesquisa. 



\section{Reuna}

No construto Motivação, houve uma tendência a concordar com os itens MOT1, MOT3, MOT4, MOT5 e MOT7, sendo a maior concordância média com o item MOT3. Por outro lado, houve uma tendência a discordar do item MOT2 e não houve tendência a concordar nem discordar do item MOT6.

Quanto à Percepção, houve uma tendência a discordar do item PER5, enquanto houve uma tendência a concordar com os demais itens deste construto, sendo que a maior concordância média ocorreu com o item PER1. Em relação à Aprendizagem houve uma tendência a concordar com os itens APR1, APR2 e APR3, sendo a maior concordância média com o item APR1. No entanto, houve uma tendência a discordar do item APR4. No construto Crenças e atitudes houve uma tendência a discordar do item CEA2, enquanto houve uma tendência a concordar com os demais itens, sendo que o item CEA4 foi o que apresentou maior concordância média. Em relação ao Estilo de vida, os indivíduos tenderam a concordar com os itens EDV1, EDV2, EDV4 e EDV6, sendo a maior concordância média com o item EDV1. Por outro lado, houve uma tendência a discordar dos itens EDV3 e EDV5, sendo que o item EDV5 teve a maior discordância média. No construto Comportamento de compra, houve uma tendência a concordar com todos os itens, sendo que o item CDC6 apresentou a maior concordância média, enquanto o item CDC1 teve a menor concordância média.

$\mathrm{Na}$ Tabela 2 são apresentados os pesos, as cargas fatoriais e as comunalidades do modelo de mensuração final. Cabe destacar que, no modelo inicial, os itens MOT1, MOT2, PER5, APR4, CEA2, EDV3, EDV4 e EDV5 apresentaram cargas fatoriais inferiores a 0,50 e também apresentaram pesos não significativos e, por estes motivos, foram excluídos da análise. Observa-se que todos os indicadores remanescentes apresentaram cargas fatoriais acima de 0,5 , significativas a $1 \%$. 



\section{Reuna}

Tabela 2. Pesos, Cargas Fatoriais e Comunalidades

\section{Indicadores}

Pesos Cargas Fatoriais Comunalidades

\section{Motivação}

Mesmo com a crise, gosto de comprar para satisfazer uma necessidade (produtos básicos).

Mesmo com a crise, gosto de comprar para satisfazer um desejo (produtos sofisticados).

Para eu comprar, é necessário um ambiente de confiança.

Para eu comprar, é necessário um ambiente livre de más notícias.

Comprar me deixa feliz.

Comprar aumenta minha autoestima.

Comprar me deixa realizado.

$$
\text { Percepção }
$$

O desemprego aumentou.

Os preços aumentaram.

A renda das pessoas diminuiu.

As pessoas estão comprando menos.

Estamos vivenciando uma crise econômica, mas já está passando.

Estamos vivenciando uma crise econômica, que deve durar por um bom tempo.

$$
\text { Aprendizagem }
$$

Acho importante assistir/ler/escutar noticiários sobre economia.

Gosto de conversar com amigos sobre economia.

Mudei meu comportamento de consumo devido a experiências passadas.

Mudei meu comportamento de consumo devido a experiências de amigos.

Crenças e atitudes

Creio que a crise vai durar muito tempo.

Creio que a crise ainda vai se agravar.

Creio que a crise vai me afetar.

Devo me preocupar com o futuro.

$\begin{array}{ccc}- & - & - \\ - & - & - \\ 0,52 & 0,62 & 0,39 \\ - & - & - \\ 0,29 & 0,78 & 0,60 \\ 0,26 & 0,77 & 0,59 \\ 0,32 & 0,79 & 0,63\end{array}$

0,63

$0,30 \quad 0,69 \quad 0,48$

$0,32 \quad 0,74 \quad 0,55$

$0,39 \quad 0,75 \quad 0,56$

$0,28 \quad 0,63 \quad 0,40$

$0,18 \quad 0,53 \quad 0,28$

$0.44+0.72$

$0,44 \quad 0,72 \quad 0,52$

$\begin{array}{lll}0,40 & 0,66 & 0,43 \\ 0,62 & 0,80 & 0,63\end{array}$

- $\quad$ - $\quad 0,80$

$\begin{array}{ccc}0,33 & 0,60 & 0,36 \\ - & - & - \\ 0,48 & 0,74 & 0,55 \\ 0,56 & 0,80 & 0,64\end{array}$


Tabela 2. Pesos, Cargas Fatoriais e Comunalidades (continuação)

\section{Indicadores}

\section{Estilo de vida}

Dou muito valor ao relacionamento com os familiares.

Dou muito valor ao relacionamento com os amigos.

Gosto muito de me divertir comprando.

Gosto muito de conforto material.

Gosto de impressionar as pessoas com os produtos que compro.

Preocupo-me em guardar dinheiro para situações imprevistas.

\section{Comportamento de compra}

Altero a periodicidade das compras.

Passo a ter mais em conta o preço quando compro.

Considero que a crise influenciou o meu consumo.

Diminuo o consumo de alguns produtos.

Substituo o consumo de um produto por outro mais barato.

Reorganizo o orçamento.

Fonte: Dados da pesquisa.
Pesos Cargas Fatoriais Comunalidades

$\begin{array}{ccc}0,57 & 0,83 & 0,68 \\ 0,40 & 0,75 & 0,57 \\ - & - & - \\ - & - & - \\ - & - & -\end{array}$

$\begin{array}{lll}0,42 & 0,54 & 0,29\end{array}$

$\begin{array}{ccc}0,57 & 0,83 & 0,68 \\ 0,40 & 0,75 & 0,57 \\ - & - & - \\ - & - & - \\ - & - & - \\ 0,42 & 0,54 & 0,29\end{array}$




\section{Reuna}

A Tabela 3 mostra a análise da validade convergente, validade discriminante, dimensionalidade e a confiabilidade dos construtos do modelo de mensuração.

Tabela 3 - Validação do modelo de mensuração

\begin{tabular}{l|c|c|c|c|c|c}
\hline \multicolumn{1}{c|}{ Construtos } & Itens & A.C. & C.C. & Dim. & AVE & VMC \\
\hline Motivação & 4 & 0,75 & 0,85 & 1 & 0,55 & 0,09 \\
Percepção & 5 & 0,70 & 0,81 & 1 & 0,45 & 0,24 \\
Aprendizagem & 3 & 0,59 & 0,78 & 1 & 0,53 & 0,13 \\
Crenças e atitudes & 3 & 0,54 & 0,76 & 1 & 0,52 & 0,23 \\
Estilo de vida & 3 & 0,51 & 0,75 & 1 & 0,51 & 0,18 \\
Comportamento de compra & 6 & 0,82 & 0,87 & 1 & 0,53 & 0,24 \\
\hline \hline
\end{tabular}

${ }^{1}$ Alfa de Cronbach, ${ }^{2}$ Confiabilidade Composta, ${ }^{3}$ Dimensionalidade, ${ }^{4}$ Variância Extraída; ${ }^{5}$ Variância Compartilha Máxima.

Fonte: Dados da pesquisa.

Os construtos aprendizagem, crenças e atitudes e estilo de vida apresentaram o índice de confiabilidade A.C. abaixo de 0,60 . No entanto, todos os construtos apresentaram o índice de confiabilidade C.C. acima de 0,60 e, dessa forma, pode-se concluir que os construtos atingiram os níveis exigidos de confiabilidade. Pelo critério de Retas Paralelas todos os construtos foram unidimensionais. Todos os construtos apresentaram AVEs maiores que 0,40 , evidenciando assim que houve validação convergente. De acordo com o critério proposto por Fornell et al (1981), houve validação discriminante para todos os construtos, uma vez que as variâncias compartilhadas máximas foram menores que as respectivas AVEs.

A Tabela 4 apresenta os resultados do modelo estrutural e a Figura 1 ilustra estes resultados. Elas refletem as mudanças que foram investigadas relacionadas ao comportamento de compra devido à recessão.

\section{Tabela 4 - Modelo estrutural}

\begin{tabular}{l|l|c|c|c|c|c}
\hline \multicolumn{1}{c|}{ Endógena } & \multicolumn{1}{|c|}{ Exógenas } & $\boldsymbol{\beta}$ & E.P.( $\boldsymbol{\beta})^{\mathbf{1}}$ & I.C.-95\% $^{2}$ & Valor-p & $\mathbf{R}^{\mathbf{2}}$ \\
\hline & Motivação & 0,13 & 0,06 & {$[0,00 ; 0,27]$} & 0,048 & \\
Comportamento de & Percepção & 0,26 & 0,07 & {$[0,10 ; 0,42]$} & 0,000 & \\
compra & Aprendizagem & 0,11 & 0,07 & {$[-0,02 ; 0,25]$} & 0,117 & $33,90 \%$ \\
& Crenças e atitudes & 0,21 & 0,07 & {$[0,05 ; 0,38]$} & 0,003 & \\
& Estilo de vida & 0,12 & 0,07 & {$[-0,02 ; 0,27]$} & 0,096 & \\
\hline \hline
\end{tabular}

${ }^{1}$ Erro Padrão; 2 Intervalo bootstrap.

Fonte: Dados da pesquisa. 
Figura 1 - Ilustração do Modelo Estrutural

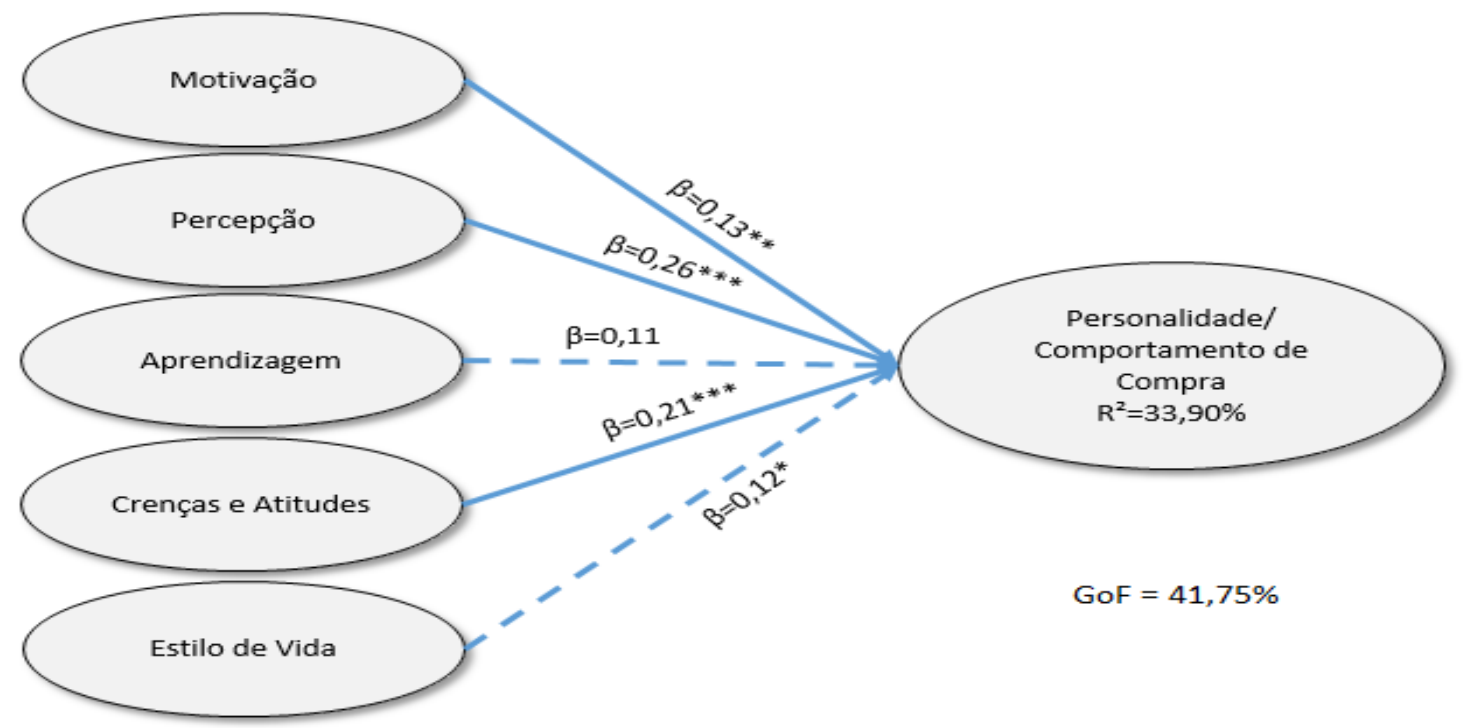

$\left.{ }^{(* \star *}\right)$ Significativo ao nível de 1\%; $\left(^{* \star}\right)$ Significativo ao nível de 5\%; (*) Significativo ao nível de 10\%.

Fonte: Dados da pesquisa.

Portanto, pode-se concluir que:

- Houve influência significativa (valor- $p=0,048)$ e positiva $(\beta=0,13[0,00 ; 0,27])$ da motivação sobre o comportamento de compra. Portanto, quanto maior a motivação para mudanças, maior será a alteração no comportamento de compra;

- Houve influência significativa (valor- $p=0,000)$ e positiva $(\beta=0,26[0,10 ; 0,42])$ da percepção sobre o comportamento de compra. Logo, quanto maior a percepção sobre a crise, maior será a mudança a alteração no comportamento de compra;

- Houve influência significativa (valor-p=0,003) e positiva $(\beta=0,21[0,05 ; 0,38])$ das crenças e atitudes sobre o comportamento de compra. Portanto, quanto maiores as crenças e atitudes maiores serão as alterações no comportamento de compra;

- Não houve influência significativa da aprendizagem (valor- $p=0,117, \beta=0,11$ [$0,02 ; 0,25])$ e do estilo de vida (valor- $p=0,096, \beta=0,12[-0,02 ; 0,27])$ sobre 0 comportamento de compra;

- As variáveis exógenas foram capazes de explicar 33,90\% do comportamento de compra, ou seja, a capacidade explicativa das variáveis exógenas foi moderada.

Para avaliar o efeito moderador das variáveis pessoais sobre o comportamento de compra, foi ajustado um modelo estrutural incluindo a interação das variáveis exógenas com a classe econômica. Para essa análise, não se utilizou a separação em grupos.

Pode-se concluir-se que houve significância do efeito moderador da classe econômica apenas na relação entre as crenças e atitudes e o comportamento de compra, e, por isso, foi ajustado posteriormente o modelo final apenas com o efeito moderador sobre as crenças e atitudes. 
A Tabela 5 e a Figura 2 ilustram os resultados encontrados do modelo estrutural final apenas com o efeito moderador da classe econômica sobre as crenças. Dessa maneira, tem-se que:

- Houve influência significativa e positiva da motivação, da percepção e do estilo de vida sobre o comportamento de compra.

- $\quad$ Não houve influência significativa da aprendizagem sobre o comportamento de compra.

- Houve significância do efeito moderador da classe econômica sobre a relação das crenças e atitudes com o comportamento de compra, sendo esse efeito moderador positivo. Dessa maneira, a influência das crenças e atitudes sobre o comportamento de compra depende da classe econômica, sendo que, quanto mais alta a classe, maior será a influência das crenças e atitudes sobre o comportamento de compra.

- $\quad$ As variáveis exógenas foram capazes de explicar $74,30 \%$ das alterações do Comportamento de Compra, ou seja, a capacidade explicativa das variáveis exógenas foi substancial.

Tabela 5. Modelo estrutural com efeito moderador de Classe Social

\begin{tabular}{|c|c|c|c|c|c|c|}
\hline Endógenas & Exógenas & $\beta$ & E.P. $(\beta)^{1}$ & I.C. $-95 \%^{2}$ & Valor-p & $\mathbf{R}^{2}$ \\
\hline \multirow{7}{*}{$\begin{array}{l}\text { Personalidade/ } \\
\text { Comportamento } \\
\text { de compra }\end{array}$} & Motivação & 0,10 & 0,04 & {$[-0,13 ; 0,19]$} & 0,020 & \multirow{7}{*}{$74,30 \%$} \\
\hline & Percepção & 0,14 & 0,05 & {$[0,04 ; 0,23]$} & 0,003 & \\
\hline & Aprendizagem & 0,02 & 0,04 & {$[-0,06 ; 0,13]$} & 0,578 & \\
\hline & Crenças e atitudes & $-0,61$ & 0,08 & {$[-0,76 ;-0,39]$} & 0,000 & \\
\hline & Estilo de vida & 0,55 & 0,04 & {$[0,42 ; 0,66]$} & 0,000 & \\
\hline & \multicolumn{5}{|c|}{ Efeito Moderador } & \\
\hline & $\begin{array}{l}\text { Crenças e atitudes } \mathrm{x} \\
\text { Classe social }\end{array}$ & 0,82 & 0,08 & {$[0,65 ; 0,98]$} & 0,000 & \\
\hline
\end{tabular}

${ }^{1}$ Erro Padrão; ${ }^{2}$ Intervalo bootstrap;GoF $=58,37 \%$.

Fonte: Dados da pesquisa. 
Figura 2 - Ilustração do modelo estrutural com efeito moderador da Classe Social

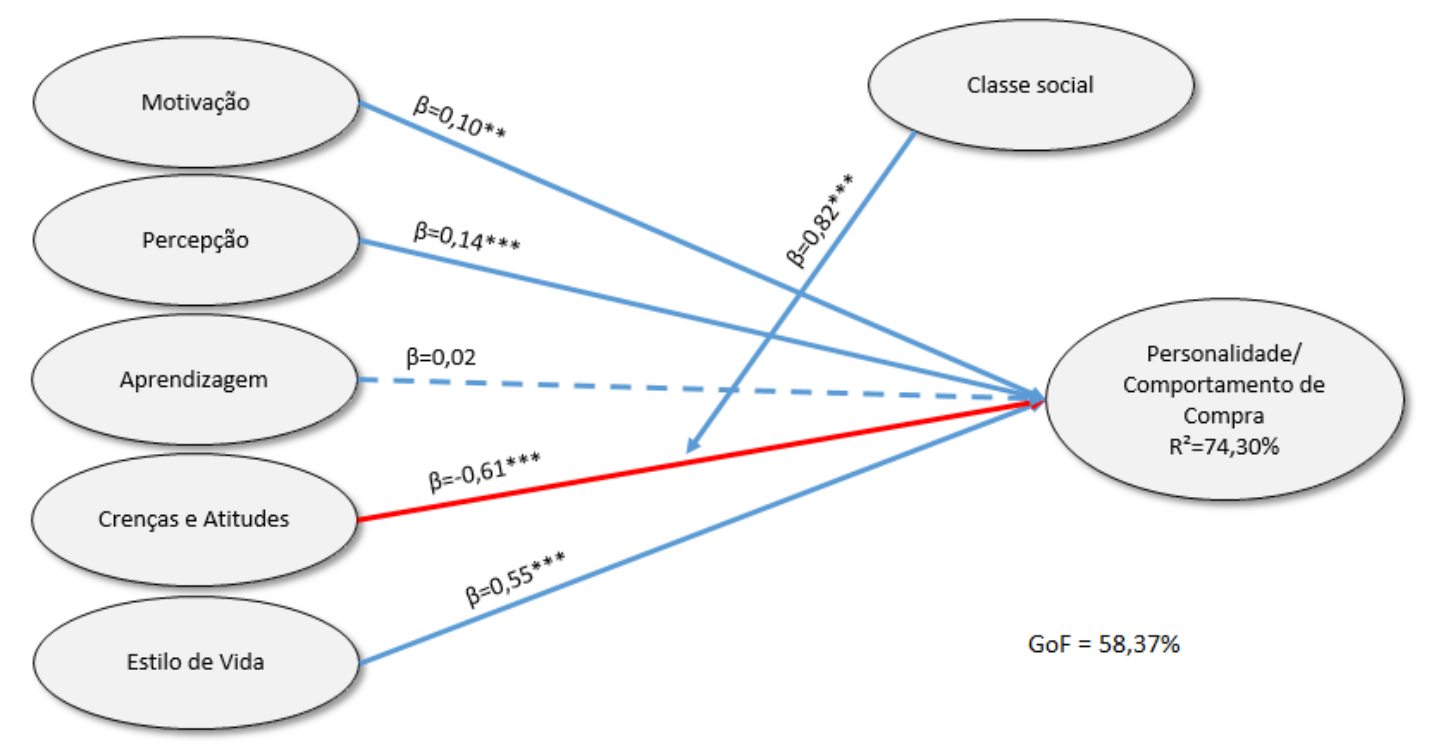

$\left.{ }^{(* \star}\right)$ Significativo ao nível de 1\%; $\left.{ }^{* *}\right)$ Significativo ao nível de 5\%; $\left({ }^{*}\right)$ Significativo ao nível de $10 \%$.

Fonte: Dados da pesquisa.

O resultado das hipóteses do modelo estrutural final é apresentado na Tabela 6. Vale destacar que as conclusões das hipóteses de $\mathrm{H} 1$ a H5 foram baseadas no modelo estrutural sem o efeito moderador, enquanto a conclusão da hipótese $\mathrm{H} 6$ foi baseada no modelo com o efeito moderador das variáveis pessoais sobre a relação entre as crenças e atitudes e o comportamento de compra.

\section{Tabela 6 - Hipóteses do modelo estrutural final}

\section{Hipóteses}

Resultado

(Classe Social)

H1: Existe um efeito positivo da Motivação sobre o Comportamento de Compra

Confirmada

H2: Existe um efeito positivo da Percepção sobre o Comportamento de Compra

Confirmada

H3: Existe um efeito positivo da Aprendizagem sobre o Comportamento de Compra

H4: Existe um efeito positivo das Crenças e Atitudes sobre o Comportamento de Compra

Não confirmada

H5: Existe um efeito positivo do Estilo de Vida sobre o Comportamento de Compra

H6: Existe um efeito moderador da Classe Social sobre o Comportamento de Compra

\section{Confirmada}

Não confirmada

Parcialmente confirmada

Fonte: Dados da pesquisa. 


\section{Considerações finais}

Pelo presente estudo pode-se perceber que mesmo com a crise econômica, as pessoas gostam de comprar para satisfazer uma necessidade. A maior parte dos respondentes acredita que para comprar é necessário um ambiente de confiança. Fatores como ambiente livre de más notícias também foi considerado importante.

No aspecto da percepção, verificou-se que as pessoas estão cientes da existência de uma crise econômica, e também não acreditam que ela já esteja passando. Fatores como aumento dos preços, queda da renda, queda do consumo e acima de tudo o aumento do desemprego foram destacados como importantes pelos respondentes.

Relacionado à aprendizagem, verifica-se que as pessoas acham importante assistir, ler e escutar noticiários sobre economia. Elas também gostam de conversar sobre economia. A maior parte delas mudou o seu comportamento de consumo devido a experiências passadas, porém não mudariam o mesmo comportamento devido a experiências de amigos.

Já nas crenças e atitudes novamente as pessoas afirmam não acreditar que a crise esteja passando. Ademais, foram unânimes em afirmar que devem se preocupar com o futuro.

Referente ao estilo de vida verifica-se uma importância muito grande dada pelos respondentes ao relacionamento com familiares. Em menor grau foi dada uma importância ao relacionamento com amigos. As pessoas discordaram em dizer que gostam de se divertir comprando, assim como negaram gostarem de impressionar as pessoas com os produtos que compram.

Relacionado ao comportamento de compra, verifica-se que os respondentes alteram a periodicidade das compras, levam mais em consideração o preço quando compram, diminuem o consumo de alguns produtos, substituem o consumo de um produto por outro mais barato e reorganizam o orçamento quando passam por um período de crise econômica. Em suma, eles consideram que a crise influência o seu consumo.

Conforme abordado no referencial teórico por autores como Sheth, Mittal e Newman (2001), Silva (2015) e Filipe, Barbosa e Amado (2015), comprovou-se que quanto maior a motivação, a percepção, as crenças e atitudes, maior será a influência significativa e positiva nas alterações do comportamento de compra.

Por outro lado, não se comprovou a influência dos construtos aprendizagem e estilo de vida sobre o comportamento do consumidor, contrariando Silva (2015), que concluiu que, em momentos de crise econômica, o consumidor passa a ter uma postura mais retraída no ato de consumir. Avaliando hábitos de compra na rede varejista de pequeno porte, Pinheiro (2017) mostra que boa parte dos consumidores manteve o seu padrão de consumo, a despeito da crise econômica. Similarmente, Reyneke, Sorokáčová e Pitt (2012) observam que as marcas de luxo foram pouco afetadas após a crise iniciada em 2008, em sintonia com os achados de Nunes, Drèze e Han (2011), que mostraram o crescimento tanto nos preços de bolsas de luxo quanto na lucratividade dos fabricantes no período imediatamente após a crise americana de 2008. Ademais, Alonso, Rodríguez e Rojo (2015) observaram que as lições trazidas pela crise econômica espanhola não surtiram efeitos para certos grupos de 
consumidores, especialmente os de maior renda e os mais jovens. Em suma, não houve influência significativa da aprendizagem e do estilo de vida sobre 0 comportamento de compra.

No modelo inicial, a capacidade explicativa das variáveis exógenas foi apenas moderada, R2 igual a 33,9\%. Conclui-se que os fatores pessoais-demográficos não exerceram influência na relação da motivação, da percepção, da aprendizagem, das crenças e atitudes e do estilo de vida com o comportamento de compra, contrariando o estudo de autores como Gade (2010), Alonso, Rodríguez e Rojo (2015).

Ao analisar somente o efeito moderador das variáveis pessoais na relação entre as crenças e atitudes e o comportamento de compra, verificou-se que houve significância. Portanto, a inclusão do efeito moderador elevou a influência de crenças e atitudes, além de tornar significativo o efeito de estilo de vida. Como resultado, o poder de explicação do modelo também foi elevado, alcançando o R2 de 74,3\%.

Como contribuições acadêmicas, pode-se elencar a identificação de variáveis determinantes das alterações do comportamento de compra em função de variações provocadas por recessão econômica. Tal assunto ainda não mereceu grande atenção por parte da academia, apesar de sua frequente ocorrência.

Em termos gerenciais, imagina-se que a identificação das alterações do comportamento do consumidor, assim como suas causas, pode ser útil aos gestores na formulação de estratégias capazes de melhorar o desempenho das organizações. Como há uma manifestação clara por parte dos respondentes no sentido de alterarem o comportamento de compra, por meio da reorganização do orçamento, com a substituição de alguns itens por similares mais baratos, fica evidente a necessidade de as organizações buscarem estratégias de mercado alinhadas à nova realidade econômica de seu público-alvo.

Cabe agora destacar as limitações da pesquisa. Uma limitação desta pesquisa prende-se ao local da aplicação. Embora a pesquisa com os respondentes tenha sido realizada em diferentes espaços públicos, tanto em meio online quanto presencial, não se tem a garantia de que a amostra tenha expressado bem a realidade demográfica de Belo Horizonte. Fica a sugestão para novas pesquisas que proponham um estudo com maior abrangência geográfica do município, assim como outras localidades no país, especialmente cidades interioranas, nas quais os efeitos da crise econômica podem ter magnitudes diferentes, mais amplas ou reduzidas.

Outra limitação encontrada foi que a pesquisa, por abordar diversos fatores psicológicos e pessoais de forma quantitativa, não se aprofundou no significado dos construtos estudados. Fica a sugestão para pesquisas qualitativas mais detalhadas a respeito de cada fator psicológico e pessoal sobre o comportamento de compra do consumidor. 


\section{Referências}

ALONSO, L. E.; RODRÍGUEZ, C. J. F.; ROJO, R. I. From consumerism to guilt: Economic crisis and discourses about consumption in Spain. Journal of Consumer Culture, v. 15, n. 1, p. 66-85, 2015.

AVELAR, C. F. P.; VEIGA, R. T. Como entender a vaidade feminina utilizando a autoestima e a personalidade. Revista de Administração de Empresas, v. 53, n. 4, p. 338-349, jul./ago. 2013.

BARBOSA, L. Moda e estilo de vida. Revista da ESPM, v. 15, ano 14, n. 5, p. 16-23, set./out. 2008.

BARROS, A. J. P.; LEHFELD, N. A. S. Fundamentos de metodologia científica. 3. ed. São Paulo: Makron Books, 2007.

BASSO, K.; RECK, D.; RECH, E. Personalidade e boca a boca: propensão ao envio e recebimento de informações. Revista de Administração de Empresas, v. 53, n. 6, p. 580591, 2013.

CORREA, S. B.; PINTO, M. L. Do "asfalto para a favela", da "favela para o asfalto": uma pesquisa etnográfica sobre a circulação e a vida social de móveis e eletrodomésticos. São Paulo: Centro de Altos Estudos da Escola Superior de Propaganda e Marketing, 2014. (Relatório Final de Pesquisa 2014). Disponível em: <http://www2.espm.br/sites/default/files/pagina/relatorio_diagramado_silvia_e_michele.pd f>. Acesso em: 15 set. 2016.

DE NARDI, M. C.; FRENCH, E.; BENSON, D. Consumption and the great recession. National Bureau of Economic Research, 2011.

DE TONI, D.; SCHULER, M. Gestão da imagem: desenvolvendo um instrumento para a configuração da imagem de produto. Revista de Administração Contemporânea, v. 11, n. 4, p. 131-151, 2007.

DREGER, A. R.; ARAÚJO, C. F.; ESPARTEL, L. B. A Interação Entre Percepção de Crowding e Motivação de Compra e Seu Efeito na Intenção de Compra. International Journal of Business Marketing, v. 2, n. 2, p. 87-97, 2017.

FILIPE, S.; BARBOSA, B.; AMADO, P. Comportamento do consumidor verde em contexto de crise econômica. Revista ESPACIOS| Vol. 36 (№ 20) Año 2015, 2015.

FORNELL, C.; LARCKER, D. Evaluating structural equation models with unobservable variables and measurement error. Journal of Marketing Research, v. 18, n. 1, p. 3950, Feb. 1981.

GADE, C. Psicologia do consumidor e da propaganda. São Paulo: EPU, 2010.

GAZZANIGA, M.; HEATHERTON, T. Ciência psicológica: mente, cérebro e comportamento. 2. ed. São Paulo: Artmed, 2005. 
GOWER, J. C. A general coefficient of similarity and some of its properties. Biometrics, v. 27, n. 4, p. 857-871, Dec. 1971.

GUILLEN, L. D. et al. Percepção da realidade. In: SIMPÓSIO INTERNACIONAL DE NEUROCIÊNCIAS DA GRANDE DOURADOS, 3., 2012. Anais...Grande Dourados: SINGraD, 2012. v. 1.

HAIR JR., J. F.et al. Análise multivariada de dados. Porto Alegre: Bookman. 2009.

KAYTAZ, M.; GUL, M. C. Consumer response to economic crisis and lessons for marketers: The Turkish experience. Journal of Business Research, v. 67, n. 1, p. 27012706, 2014.

KOKSAL, H.; OZGUL, E. The relationship between marketing strategies and performance in an economic crisis. Marketing Intelligence\& Planning, v. 25, n. 4, p. 326-342, 2007.

KOSICKA-GEBSKA, M.; GEBSKI, J. Impact of economic crisis on consumer behaviour towards meat. Acta Scientiarum Polonorum. Oeconomia, v. 12, n. 3, 2013.

MARINO, M. R. G. B.; SAMPAIO, C. A. Brasil idoso: desafios para o consumo. Identidade Científica, v. 4, n. 1, p. 22-40, 2013.

MANSOOR, D.; JALAL, A. The global business crisis and consumer behavior: Kingdom of Bahrain as a case study. International Journal of Business and Management, v. 6, n. 1, p. 104, 2011.

McCRACKEN, G. Cultura e consumo: uma explicação teórica da estrutura e do movimento do significado cultural dos bens de consumo. Revista de Administração de Empresas, v. 47, n. 1, p. 99-115, jan./mar. 2007.

MENDES, G. A.; AQUINO, C. A. Comportamento do consumidor: uma análise das principais influências individuais e coletivas. Essentia - Revista de Cultura, Ciência e Tecnologia da UVA, v. 15, n. 2, 2015.

MEYER, B. D.; SULLIVAN, J. X. Consumption and income inequality and the great recession. American Economic Review, v. 103, n. 3, p. 178-83, 2013.

NUNES, J. C.; DRÈZE, X.; HAN, Young J. Conspicuous consumption in a recession: Toning it down or turning it up? Journal of Consumer Psychology, v. 21, n. 2, p. 199205, 2011.

PINHEIRO, A. F. A. A interferência da crise econômica no comportamento do consumidor, em relação aos pequenos comércios locais. South American Development Society Journal, v. 2, n. 5, p. 27-41, 2017.

REYNEKE, M.; SOROKÁČOVÁ, A.; PITT, L.. Managing brands in times of economic downturn: How do luxury brands fare? Journal of Brand Management, v. 19, n. 6, p. 457466, 2012.

SCHIFFMAN, L. G; KANUK, L. L. Consumer Behavior. $7^{\text {th }}$ ed. New York: Prentice Hall, 2000. 
SECCO, C. F. C.; OLIVEIRA, E. M.; AMORIM, R. M. Comportamento do consumidor: fatores que determinam o processo de compra no mercado varejista em Palmas - TO. Revista Científica do ITPAC, v. 7, n. 3, p. 1-13, 2014.

SHETH, N. J.; MITTAL, B.; NEWMAN, I. B. Comportamento do Cliente: indo além do comportamento do consumidor. São Paulo: Atlas, 2001.

SILVA, C. O. A mudança de hábitos de consumo da classe média em Portugal, no contexto da crise atual. 2015. 170 f. Dissertação (Mestrado em Sociologia) Universidade de Minho, Braga, 2015.

TEIXEIRA, M. A. M. F. As marcas em tempo de crise. Dissertação (Mestrado em Marketing) - Universidade Católica Portuguesa, 2015. 